\title{
Nanotechnology and its applications in fashion design in 2020
}

\section{Sarah de Godoy ${ }^{a}$ Milton Sogabe ${ }^{b}$ \\ Universidade Anhembi Morumbi}

This article identifies, systematizes, analyzes and maps proposals and experiences for the application of nanotechnology to the textile industry and as hypotheses in which fabrics, classified as "smart", have been fed industrially in fashion design in 2020. Therefore, it is considered design and human beings have an inseparable link, making it essential to raise aspects not yet fully mapped of the relationship of "smart fabrics", that is, those sought through the implementation of nanotechnology in stages of the textile production process, with design fashion, which aims to establish an interface between human beings and clothing. In this sense, the method used for this qualitative investigation essentially contemplates a descriptive-observational modality of study of recognition.

The choice of this theme is due to the scientific development of nanotechnology, which allows, through its technological manipulation, the modification and reinvention of materials and processes, so that structures can work at molecular and atomic levels, self-organizing and realigning itself in response to external stimuli, becoming in the end a resource for the improvement of textiles (JORDÃO, 2009). However, despite constant research and the development of the technical capacity of this resource, the study of the relationship between "smart fabrics" and fashion design is still quite scarce. It is known that such information is fundamental for the consolidation of this innovation process in the textile industry and, consequently, for the satisfaction of users (SENAI-SP, 2012; SOLOMON, 2011; SAWHNEY et al., 2008; COLCHESTER, 2007).

In addition, according to May (2007, p.164), there are several products on the market that use nanotechnology without the knowledge of society, since the products are not labeled with this information and there is no

\section{Orcid number:}

a000-0003-1143-2581 b $0000-0003-1286-9013$ specific regulation. Among these products are fabrics. The verification of this data makes this article pertinent to society, which is insipient to the subject. And, from a marketing point of view, the research is relevant, as it may help to educate fashion designers, brands and users about the "smart fabrics" available.

The combination of the above factors and the understanding of the situations in which "smart fabrics" are integrated into fashion design are relevant elements to the theme of the conference "Design as common good", since the research seeks to identify, systematize, analyze and map, through the proposed methodological tools, paths and directions of fashion design, addressing relevant issues such as their role in contemporary times, as well as directing new possibilities, using "smart fabrics" as a material resource in this process, serving as a parallel for other converging needs in other areas.

The results of this study thus provide inputs to fashion designers and users, as well as associations of technical standards, the textile industry and the innovation sector, seeking to fill the gap identified about the lack of information in relation to situations where nanotechnology is being integrated into fashion design in 2020.

KEYWORDS

Fabrics, Fashion design, Interface, Nanotechnology, Smart fabrics 